\section{TUBERCLE BACILLI IN ADDISON'S DISEASE.} To the Editor of THE LANCET.

SIR,-In your last week's number there is an interesting note on the discovery of tubercle bacilli in the supra-renal capsules in Addison's disease. I should be obliged if you will permit me to point out that in a clinical lecture at King's College Hospital last month I showed the enlarged and caseated capsules in a well-marked and fatal case of Addison's disease, and told my class, that after repeated and most careful examinations for the special object of detecting tubercle bacilli, one of our best modern microscopists and bacteriologists had failed to find any bacilli. It is therefore clear that in this respect, as in some others, cases of Addison's disease differ, and that we must not too hastily assume that it is always a strictly tubercular affection.

I am, Sir, yours, truly,

George-st. Hanover-sq., June 14th, 1886. JoHN CunNow.

\section{ELECTROLYSIS IN STRICTURE OF THE URETHRA.}

To the Editor of THE LANCET.

Sir,--There are one or two points raised by Mr. Hurry Fenwick in The Lancet of June 5th to which I must venture to take some exception. He implies in his first paragraph that the currents I was using were strong currents, and in his second speaks of their burning the cicatrix. With regard to the first point, I can only say that the currents $I$ used were very weak, and they caused no pain. I could very easily bear them on my own skin; and with regard to the second, I can positively assert that they do not burn. I have always been careful to point out that the object to be attained was softening of the tissues and gradual chemical change, not cauterisation. That a caustic alkali is liberated in the urethra is quite true; but it is only in small amount, and I do not believe this represents 'by any means all that takes place. Of the value of electricity in certain cases of stricture I have no doubt, but what we now require to know is what is the nature of the changes that take place in certain tissues under varying current strengths, a point which $I$ am at present engaged in inv $\_$stigating. This question could never be answered till we had some ready means of measuring current strengths; this means we now possess in the voltmeter. With regard to "reflex shock," excepting in the first case in which I used electricity, when of course my experience was nil, I have never had a rise of temperature or any constitutional disturbance, and $I$ am confident that in the electric current we have a safe and certain therapeutic agent.

I remain, Sir, yours faithfully,

Harley-street, June, 1886. W. Bruce Clarke.

\section{UNIVERSITY OF DURHAM COLLEGE OF MEDICINE.}

To the Editor of THe LaNCET.

SIR,-The Council of the University of Durham College of Medicine desire me to draw your attention to the following statement in answer to certain observations made by Sir John Lubbock and Professor Sir Henry Roscoe during the discussion on the Medical Acts Amendment Bill in the Committee of the House of Commons on Monday, the 31st ult. Sir John Lubbock is reported to have stated that "he should say there were not more than twenty or thirty medical undergraduates at the Durham University." As a matter of fact the medical undergraduates in attendance at the University during the last year (1885) numbered 234 (see the University Calendar, 1886), of whom many were already qualified to practise; and the number of individual entries for the examinations for the degrees in medicine (excluding those for the special arts examinations for the degrees in medicine) during the period from May 1st, 1885, to April $30 \mathrm{th}, 1886$, was 245 . Of this number, 186 passed the various examinations for the degrees, of whom 63 graduated, 4: passed the first examination (old regs.), 51 the first examination (new regs.), and 27 the second examination (new regs.) I am, Sir, yours faithfully,

LUKR Arirstrong, M.D.

June 14th, 1886 . Regist. Univ. of Durh. Col. of Med.

\section{THE POISONOUS EFFECTS OF COCAINE.}

To the Editor of THA LANCET.

SIR,-Cnder the above heading there appears a letter in THE LANCET of June 12th, in which a case is related with symptoms of poisoning after the free application of from twenty to thirty drops of a 4 per cent. solution of hydrochlorate of cocaine to the teeth and gums. It may be interesting to your readers to mention a cuse of ulceration at the back of the tongue of so painful a nature that it has necessitated the frequent application of a 20 per cent. solution of cocaine, so that for the past month about two drachms of the 20 per cent. solution, that is twenty-four grains, have been applied to the back of the mouth and throat in every twenty-four hours without any untoward constitutional symptoms. The pain of swallowing has been so great that the cocaine has had to be freely used to deaden sensibility previously to taking nourishment. The only untoward effect $\mathrm{I}$ have noticed is some interference for a short time with the act of deglutition when the cocaine is brought too freely in contact with the palate. The sensitiveness of the palate is interfered with, and reflex action, a necessity of deglutition, destroyed for a brief period. Power is soon regained, but insensitiveness to pain continues for some time afterwards. Cocaine solutions are known to have an exceptional disposition to favour the development of germ life, and should always be freshly prepared for use, or some unexpected action may be produced.-I am Sir, yours obediently, Wokingham, June 16th, 1886. J. G. BARFORD,

\section{BIRMINGHAM. \\ (From our own Correspondent.)}

THE BOARD OF GUARDIANS AND THEIR MEDICAL OFFICRR. Tre relations between the guardians and their medical officer have been strained for some months past, as already noted in THe LANCET. An inquiry was held by the Local Government Board, and at a meeting of the guardians held on March 31st a letter was read from the central authority calling upon the medical officer to resign his appointment. Since this time an endeavour has been made to prevent the resignation taking effect, and to create a reaction in favour of the official. On the principle that the punishment was greater than demanded by the alleged error, a memorial was signed by a number of influential members of the Board of Guardians, asking for the question to be reconsidered on the ground of the long period of sixteen years service on the part of the medical officer, with singularly few complaints and a faithful discharge of duty. A special meeting of the guardians was held on the 16th inst, and the majority affirmed the resolution of the Local Government Board. Thus, after much criticism and discussion, a valuable officer is forced to take his departure under circumstances which considerably mar his chances in the future, and at a time of life when it is difficult to make a fresh start in practice, after a long period of routine work to which he devoted his best years and abilities in the performance of an ungrateful task.

$$
\text { HEALTH OF THE BOROUGH. }
$$

The able report of the medical oflicer of health for the year 1885 gives a very favourable account of the sanitary condition of this large town, and points out that the absolute number of deaths is less, with two exceptions, than in any year since 1870 . This is rendered much more gratifying by the facts elicited, that there is a diminished mortality in infants under one year of age, and in children under five years of age; and also a lessened mortality from zymotic or preventable disease. A higher death age, too, than has been observed in previous years is worthy of comment. Comparison shows that whilst the density of Birmingham is exceeded by only four of the large towns, and is considerably greater than the other seven taken for the estimate, its deathrate is least of all. At the present rate of improvement, the inhabitants may take comfort in the knowledge that smoke and dirt were not the essential elements of the mortality of manufacturing towns.

REMARKABLE CASF OF POISONING.

The coroner for Central Warwickshire held an inquest touching the death of a child aged five years on June 15th. 